\title{
Influence of Processing Conditions on the Weld Line in Doubly Injection-Molded Glassy Polymers: Microindentation Hardness Study
}

\author{
M. BOYANOVA*, F. J. BALTÁ CALLEJA**, S. FAKIROV* \\ Instituto de Estructura de la Materia, CSIC, Serrano 119, 28006 Madrid, \\ Spain
}

\section{KUEHNERT, G. MENNIG}

Professur fuer Kunststoffverarbeitungstechnik, Technische Universitaet Chemnitz Reichenhainer Str. 70, 09126 Chemnitz, Germany

Key words: Microhardness, PC, PS, Injection molding, Weld line

$$
\text { Paper submitted to Advances in Polymer Technology }
$$

July, 2003

* Permanent address: Sofia University, Laboratory on Polymers,

1126 Sofia, Bulgaria

** Author for correspondence. E-mail: imtb421@iem.cfmac.csic.es 


\begin{abstract}
The microhardness $(\mathrm{H})$ technique has been used to characterize the quality of the weld line in injection-molded tensile bars from two-component machine in which both melt streams of the same material can be independently controlled. More specific, the influence of melt temperature and indentation location (closer or further from the sample edge parallel to the injection direction and across the weld line) has been followed on polycarbonate (PC) and polystyrene (PS) glassy samples. For both polymers at lower melt temperatures a strong $\mathrm{H}$ decrease (between 15 and $50 \%)$ followed by a sharp increase in a narrow distance $(0.20$ $-0.25 \mathrm{~mm}$ ), is observed. When the melt temperature increases up to $300^{\circ} \mathrm{C}$ (for PC) and $270^{\circ} \mathrm{C}$ (for PS) a much smaller $\mathrm{H}$ decrease is observed in the central part of the samples. However, closer to the tensile bar edges $(2 \mathrm{~mm})$ the weld line remains undetectable by microhardness measurements. The present results reveal that the processing conditions affect the broadening of the weld line through the conditions for effective mutual interdiffusion of chains from the two fronts coming from opposite sides.
\end{abstract}




\section{Introduction}

Earlier studies [1] have shown that microhardness may provide useful information about the correlation of processing parameters between near and at the weld line or knit line, i.e. the region where separated melt fronts reunite. In practice, weld lines occur in injection molding, i.e. after a flow obstacle or in case of multiple gating for melt streams of the same material or in case of two component injection molding for melt streams of different polymer materials [2]. In general, the presence of a weld line has an effect on the surface appearance and the mechanical properties of the molded parts. [3]

The use of microhardness $(\mathrm{H})$ to characterize changes in microstructure, molecular orientation and micromechanical properties of injection-molded polymer materials has been the object of increasing interest [4-7]. In addition, it is known that process variables induce important changes in the microstructure and properties of the molded material [8-9]. Hardness variations often occur on the surface and across the thickness of the molded samples. As a result, the mechanical properties can be controlled by processing variables such as melt and mold temperature, injection pressure, etc. [5].

Recently we reported [10] a study of the microindentation hardness value across the weld line arising when the two opposite flow fronts are filling the cavity of the mold using two glassy polymers, polycarbonate (PC) and polystyrene (PS). A large hardness difference between $\mathrm{H}$ measured away from the weld line and $\mathrm{H}$ measured at $z=0\left(\mathrm{H}_{\min }\right)$ was found. For PC this difference was about $20 \mathrm{MPa}(\sim 14 \%)$ while for PS it was larger than $50 \mathrm{MPa}(\sim 30 \%)$ [10]. The $\mathrm{H}$ measurement along the injection direction $z$ for the PC and PS samples containing a pigment for better visualization of the flow front, was also performed [10] and the $\mathrm{H}_{\min }$ value defining the weld line was identified. Asymmetry of $\mathrm{H}$ values between the sample side containing the pigment and the other side without pigment was observed. For both polymers higher $\mathrm{H}$ values measured on the side containing the pigment show the hardening effect of the pigment within the polymer. Such an asymmetry is a contrast to the case of no pigment [10]. 
The aim of the present work is to extend the above studies [10] on the two glassy polymers (PC and PS) processed using a two-component injection molding system. Specifically, we wish to examine the effect of processing temperature on the $\mathrm{H}$ value across the weld line arising when the two opposite flow fronts are filling the cavity of the mold. In addition, for the sake of comparison the measurements are carried out close to the edge and on the middle of the sample as shown schematically in Fig. 1.

\section{Experimental}

\section{Materials}

Polycarbonate (Makrolon 3200, Bayer) with the glass transition temperature $\mathrm{T}_{\mathrm{g}}=$ $150^{\circ} \mathrm{C}[11]$ and high molecular weight polystyrene (PS-168 N BASF) $\left(\mathrm{T}_{\mathrm{g}}=105^{\circ} \mathrm{C}\right.$ [11]) samples were used in this study. Amorphous brittle polymers like PS are well known for their weak weld line strength. Parts from an amorphous ductile material like polycarbonate containing a weld line can reach almost a $100 \%$ of the strength of the raw material. Table 1 shows some selected properties.

Table 1: Materials properties

\begin{tabular}{|c|c|c|}
\hline Property & Makrolon 3200 & PS $168 \mathrm{~N}$ \\
\hline Density $\left[\mathrm{g} / \mathrm{cm}^{3}\right]$ & $1.20 *$ & $1.05 * *$ \\
\hline Tensile modulus [MPa] & $2400^{*}$ & $3300 * *$ \\
\hline Tensile strength without weld line [MPa] & $63^{*}$ & $59 * *$ \\
\hline $\begin{array}{c}\text { Tensile strength with weld line [MPa] } \\
\text { (lower melt temperature) }\end{array}$ & $63 * * *$ & $33 * * *$ \\
\hline $\begin{array}{l}\text { Tensile strength with weld line }[\mathrm{MPa}] \\
\text { (higher melt temperature) }\end{array}$ & $63 * * *$ & $41 * * *$ \\
\hline
\end{tabular}

* Database of BAYER AG, Leverkusen (Germany); **Database of BASF AG, Ludwigshafen (Germany) ,; *** measured at TUC [12] 


\section{Processing}

The moldings were prepared in the form of ISO 3167 Typ A tensile bars (gauge length $170 \mathrm{~mm}$, thickness $4 \mathrm{~mm}$ and width $10 \mathrm{~mm}$ ) using a two-component injection molding machine in which both melt streams (of same material, though differently colored by 2 wt.- $\%$ of PS or PC colorbatch respectively) can be controlled independently (Fig. 1a). The bars were molded using for PC a melt temperature $\mathrm{T}_{\mathrm{m}}$ of $270^{\circ} \mathrm{C}$ and atso $300^{\circ} \mathrm{C}$ and for botheseses a mold temperature $\mathrm{T}_{\mathrm{w}}$ $=80^{\circ} \mathrm{C}$. The injection pressure for both melt fronts was $170 \times 10^{5} \mathrm{~Pa}$ and $/$ speed of the melt front was $200 \mathrm{~mm} \mathrm{~s}^{-1}$. In the case of PS, values of $\mathrm{T}_{\mathrm{m}}=230 \% \mathrm{C}$ and $270^{\circ} \mathrm{C}$ and $\mathrm{T}_{\mathrm{w}}=50 \% \mathrm{C}$ were used. The injection pressure here and the speed of the melt front were $110 \times 10^{5} \mathrm{~Pa}$ and $200 \mathrm{~mm} \mathrm{~s}^{-1}$, respectively. The different melt temperatures were chosen to investigate their influence on the tensile strength and surface (V-notch) effects of weld lines [12]. A higher melt temperature usually increases the strength (Table 1)

From the injection molded tensile bars the central part containing the weld line with a total length of $20 \mathrm{~mm}$ was cut and embedded in an epoxy resin in order to enhance the sample fixing during subsequent measurements (Fig. 1b, $z$ is flow direction).

\section{Techniques}

Microhardness was measured across the weld line at the surface of each of the molding using a microindentation tester with a Vickers square based pyramidal diamond indenter. The hardness value (in $\mathrm{MPa}$ ) was derived from the residual projected diagonal impression using, $H=k P / d^{2}$, where $\mathrm{P}$ is the applied force in $\mathrm{N}, k$ is a geometrical constant equal to 1,854 , and $d$ is the length of the projected indentation diagonal in $\mathrm{m}$. A load of $\mathrm{P}=0,25 \mathrm{~N}$ and a loading cycle of $6 \mathrm{~s}$ were used. Special care was taken to make indentations whose diagonal were parallel and perpendicular to the injection direction $(z)$.

The injection molded sample with the position of the weld line and the location of the measurements across the weld line are shown schematically in Fig 1. 
Optical micrographs from the indentation surface were taken using a light microscope in a reflection mode and magnification objective of $\mathrm{x} 40$.

\section{Results and Discussion}

Microindentation study in doubly injection molded PC

Fig. 2 shows the optical micrograph of the surface of a PC sample after performing several indentations. In contrast to previous measurements on the same systems [10] in which practically only one or two measurements characterized the deep decrease of $\mathrm{H}$ on the weld line, in the present case the same line is defined by $5-10$ identations which makes the reported $\mathrm{H}$ decrease more reliable. The $\mathrm{H}$ values are then plotted as a function of the distance from the weld line $z$.

Fig. 3 illustrates the $\mathrm{H}$ variation on the surfaces of the molding along the injection direction, $z$, for the PC samples with a melt temperature of $230^{\circ} \mathrm{C}$ taken at $2 \mathrm{~mm}$ (Fig. $3 a$ ) and $5 \mathrm{~mm}$ (Fig $3 b$ ) from the edge. We denote the position of the boundary plane as $z=0$. Results clearly show the gradual $\mathrm{H}$ decrease for both 2 and $5 \mathrm{~mm}$ measurements along the $z$ direction, until a minimum value at $z=0$ is reached. Then, one observes a further increase of $\mathrm{H}$ when indenting away from $z=0$. The asymmetry of the hardness profile about $z=0$ is evident in both cases (Fig $3 a$ and b). The weld line zone containing the $\mathrm{H}$ changes is defined in the PC case within a $0,20-0,25 \mathrm{~mm}$ region which is much smaller than the reported one $(1 \mathrm{~mm})$ for the same polymers previously [10].

Most interesting is to note the large hardness difference found between $\mathrm{H}$ measured away from the weld line and $\mathrm{H}$ measured at $z=0\left(\mathrm{H}_{\min }\right)$. For PC this difference is about $50 \mathrm{MPa}(\sim 30 \%)$ for both measurements (Fig. $3 a$ and $b$ ).

The asymmetry of $\mathrm{H}$ values, between the sample side containing the pigment (lefthand side) and the side without pigment (right-hand side) is again observed for both measurements (at 2 and $5 \mathrm{~mm}$ from edge, Fig 1). Higher $\mathrm{H}$ values on the side containing the pigment show the hardening effect of the pigment within the polymer. 
It should be noted that $\mathrm{H}$ measurements at a distance of $8 \mathrm{~mm}$ from the same sample edge (Fig. 1) were also performed. The values obtained are the same as those measured at $2 \mathrm{~mm}$ distance from the edge (Fig. 1). For this reason the data of these measurements (at $8 \mathrm{~mm}$ from the edge) are not plotted in Fig. 3 as well as on the subsequent ones.

Fig. 4 shows the $\mathrm{H}$ data taken in the same way again on the $\mathrm{PC}$ sample processed at a melt temperature of $300^{\circ} \mathrm{C}$. Comparison of the data from Figs. 3 and 4 allows one to make two important conclusions illustrating the difference between the two cases, i.e. the effect of melt temperature on microhardness. First of all, measurements performed at $2 \mathrm{~mm}$ from the edge (Fig. 1) do not detect any weld line (Fig. 3a), and secondly, the measurements at $5 \mathrm{~mm}$ from the edge (Fig. $3 b$ ) show a slight decrease (around $20 \mathrm{MPa}$, i.e. $\sim 15 \%$ ). What can be the reason for the different microhardness behavior as depending on the melt temperature and location of measurement?

The observation that injection-molded samples with higher melt temperature $\left(300^{\circ} \mathrm{C}\right.$, Fig. 4) show a much smaller microhardness depression at the weld line (Fig. 4b) and even any (Fig. 4a) as compared to those molded with a lower melt temperature $\left(270^{\circ} \mathrm{C}\right)$ (Fig. 3) could be related with the diffusion conditions when the two polymer fronts meet. Taking into account the fact that the mold temperature and the $\mathrm{T}_{\mathrm{g}}$ are the same $\left(\mathrm{T}_{\mathrm{w}}=80^{\circ} \mathrm{C}\right.$ and $\left.\mathrm{T}_{\mathrm{g}}=148^{\circ} \mathrm{C}\right)$ as well as the flow front speed $\left(200 \mathrm{mms}^{-1}\right)$ it is quite clear that the temperature of the "melt", when the two fronts meet, should be lower if the starting temperature of the melt is lower. This means, that the opportunities for mutual diffusion of chains resulting in their randomization and disappearing or at least making the welding line narrower, are not favorable. Increasing the melt temperature, let us say from $270^{\circ} \mathrm{C}$ to $300^{\circ} \mathrm{C}$ in the present case, leads to a strong decrease of the welding line (Fig. $4 b$ ) and even to its disappearance (Fig. 4a).

The same conclusion was drawn in the previous measurements but using two polymers (PC and PS) and different processing conditions $\left(\mathrm{T}_{\mathrm{m}}, \mathrm{T}_{\mathrm{w}}\right)$ for each one $[10]$. 
Regarding the effect of the measuring location, namely, closer or further apart from the sample edge (or in other words from the mold walls) it should be noted that the differences observed (Figs. 3 and 4) are also related to the temperature of the two molten polymer fronts at the instant they meet. Let us try to estimate the temperature difference of the melt closer or further from the mold walls during the flow. For this we have to take into account the observation that the two flow fronts as well as the welding "line" are not planar but rather parabolical, particularly the front containing the pigment. If so, the central part of the mold cavity contacts the melt first (top of the "cone") followed by the side walls of cavity (base of the "cone"). In such a case, when the side parts of the mold are filled up with the melt, the side walls have been preheated because of the quick heat conduction in the mold. Such a difference in the temperature of the molded parts results in larger under-cooling of the melt in the central part of the mold cavity as compared with both sides. The latter offer better diffusion conditions at the weld line than the central part. Obviously, this is the reason for the different $\mathrm{H}$ values through the welding line measured closer and/or further apart from the sample edge.

\section{$\underline{\text { Microindentation study in doubly injection molded PS }}$}

The above interpretation of the effect of melt temperature and the location of the microindentations across the welding line, as derived from the experiments with PC, seems to be supported by the analogous measurements on PS. Again two melt temperatures $\left(230^{\circ} \mathrm{C}\right.$ and $\left.270^{\circ} \mathrm{C}\right)$ and the same mold temperatures $\left(\mathrm{T}_{\mathrm{w}}=50^{\circ} \mathrm{C}\right)$ in both cases are used. Similarly to the previous case (Figs. 3 and 4) the measurement of $\mathrm{H}$ are carried out closer $(2 \mathrm{~mm})$ or further apart $(5 \mathrm{~mm})$ from the edge of the sample (Fig. 1). The obtained $\mathrm{H}$ values measured at the surface of the molding along the injection direction $(z)$ through the welding line are plotted as a function $z$ in Figs. 5 and 6 for the two melt temperatures, $230^{\circ} \mathrm{C}$ and $270^{\circ} \mathrm{C}$, respectively.

As one can see from Fig. 5 for the lower melt temperature $\left(230^{\circ} \mathrm{C}\right)$ a well defined strong (more than 50\%) H-decrease followed by a $\mathrm{H}$-increase at both measuring zones ( 2 and $5 \mathrm{~mm}$ from the edge of the sample, Fig. $5 a$ and $b$, respectively) is observed. In addition, this drastic change in the $\mathrm{H}$ values takes place in a quite narrow $z$-range (about $0,20-0,25 \mathrm{~mm}$ ). The width of the weld line is a similar to 
that for the case of PC (Figs. 3 and 4), while the drop in the $\mathrm{H}$ values is much larger. In this case the effect of pigment on the microhardness far-away from the weld line is not so clear as in the case of PC (Figs. 3 and 4).

When the melt temperature is increased up to $270^{\circ} \mathrm{C}$ the situation looks rather different as can be seen from Fig. 6. While at $5 \mathrm{~mm}$ from the edge of the sample (Fig. $6 b$ ) a small drop (about 10\%) in the $\mathrm{H}$ value across the welding line is observed, closer to the edge such a drop is even missing (Fig. 6a). This result is similar to the case of PC at the higher melt temperature (Fig. 4). Therefore, this finding supports the interpretation given before, i.e. again the dominating role of the melt temperature, particularly when the two opposite polymer fronts meet, is stressed. One should note here that the case under discussion is very close to the well-studied phenomenon of physical healing $[13,14]$ where the mutual interdiffusion is determined by chain flexibility and diffusion conditions (temperature, molecular weight, etc.).

\section{Conclusions}

1. In accordance with previous results [10], it is demonstrated that microhardness is an adequate technique which can accurately define the region across the weld line in injection molded parts and can furnish information about the local degree of mutual interdiffusion within the weld boundary.

2. The broadening of the weld line (expressed in the microhardness changes across the $z=0$ ) depends primarily on the mutual chain diffusion from the two polymer fronts coming from opposite sides.

3. It is shown that the main factors affecting the quality of the welding on line $z=0$ are: on the one hand the $T_{g}$ of the polymer under investigation, and on the other, the processing conditions (melt temperature, mold temperature, injection speed and others). 


\section{Acknowledgements}

Grateful acknowledgement is due to the MCYT, Spain (Grant BFM2000-1474) and DFG, Germany (Me 563/22-2) for the generous support of this investigation. One of us (S.F.) deeply appreciates the financial support of NATO - Spain for the award of a fellowship making possible his stay at Instituto de Estructura de la Materia, CSIC, Madrid, where this study was carried out. S.F. and M.B. acknowledge also the hospitality of the same Institute. 


\section{References}

1. Rueda, D.R.; Baltá Calleja, F.J.; Bayer, R.K. J Mater Sci 1981, 16, 3371.

2. Rueda, D.R.; Bayer, R.K.; Baltá Calleja, F.J.; Zachmann, H.G. J Macromol Sci Phys 1989, B 28, 265.

3. Baltá Calleja, F.J.; Baranowska, J.; Rueda, D.R.; Bayer, R.K. J Mater Sci 1993, 28,6074 .

4. Rueda, D.R.; Kubera, L.; Baltá Calleja, F.J.; Bayer, R.K. J Mater Sci Lett 1993, 12,1140 .

5. Birley, A.W.; Hawort, B.; Batchelor, J. Physics of Plastics: Processing, Properties and Materials Engineering; Hanser Publ: Munich, 1992

6. Eder, G.; Janeschitz-Kriegl, H.; Liedauer, S. Prog Polym Sci 1990, 15, 629

7. Heck, S.; Poellet, P. VDI-Beri. 1989, 731, 167

8. Nguyen-Chung, T.; Plichta, C.; Mennig, G. Rheol Acta 1998, 37, 299

9. Mennig, G. in Karger-Kocsis, J., Polypropylene - Structure, blends and composites; Chapmann \& Hall 1995, 1, 205-226

10. Garcia Gutierrez, M.C.; Rueda, D.R.; Baltá Calleja, F.J.; Kuehnert, I.; Mennig, G. J Mater Sci Lett 1999, 18, 1237

11. N. N., Moldflow Materials database MPI 4.1, 2004

12. Mennig, G., Kuehnert, I., Report DFG 1999

13. Kausch, H.H. Polymer Fracture, Springer: Heidelberg-New York, 1987

14. Wool, R.P. Polymer Interfaces, Hanser: Munich-New York, 1996 


\section{Figure captions}

FIGURE 1. Schematic representation of a doubly injection molded sample showing front weld line and the measuring lines (at 2,5 and $8 \mathrm{~mm}$ from the sample edge) parallel to the injection direction and across the weld line.

FIGURE 2. Optical micrograph of indentations at the surface of an injection molded PC sample near the weld line area (left-hand side with pigment) .

FIGURE 3. Microhardness, $H$, measured at the surface of the molding along the injection direction, $z$, for $\mathrm{PC}$ with melt temperature of $270^{\circ} \mathrm{C}$. Arrows denote the direction of the two opposing fronts: measurements are performed along the injection direction (Fig. 1) at a distance from the sample edge as follows: a) -2 $\mathrm{mm}$, and b) $-5 \mathrm{~mm}$. The left part of the sample contains a pigment. The right one does not contain the pigment.

FIGURE 4. Microhardness, $H$, measured at the surface of the molding along the injection direction, $z$, for $\mathrm{PC}$ with melt temperature of $300^{\circ} \mathrm{C}$. Arrows denote the direction of the two opposing fronts: measurements are performed along the injection direction (Fig. 1) at a distance from the sample edge as follows: a) -2 $\mathrm{mm}$, and b) $-5 \mathrm{~mm}$. The left part of the sample contains the pigment.

FIGURE 5. Microhardness, $H$, measured at the surface of the molding along the injection direction, $z$, for PS with a melt temperature of $230^{\circ} \mathrm{C}$. Arrows denote the direction of the two opposing fronts: measurements are performed along the injection direction (Fig. 1) at distance from the sample edge: a) $-2 \mathrm{~mm}$, and b) -5 $\mathrm{mm}$. Left part of the sample contains the pigment.

FIGURE 6. Microhardness, $H$, measured at the surface of the molding along the injection direction, $z$, for PS with a melt temperature of $270^{\circ} \mathrm{C}$. Arrows denote the direction of the two opposing fronts: measurements are performed along the injection direction (Fig. 1) at distance from the sample edge: a) $-2 \mathrm{~mm}$, and b) -5 $\mathrm{mm}$. Left part of the sample contains the pigment. 


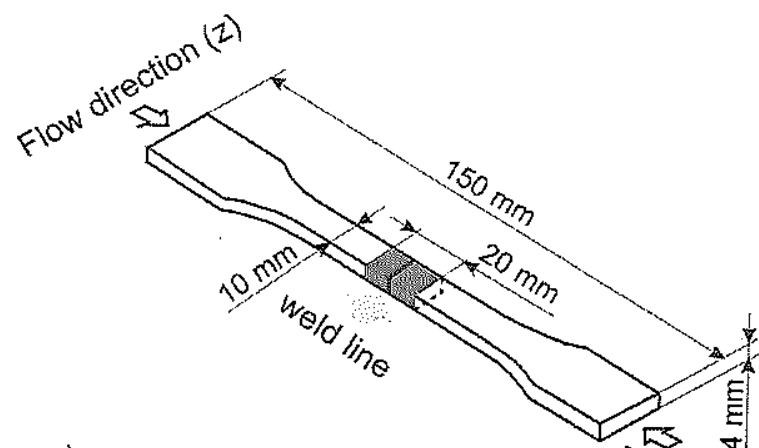

a)

b)

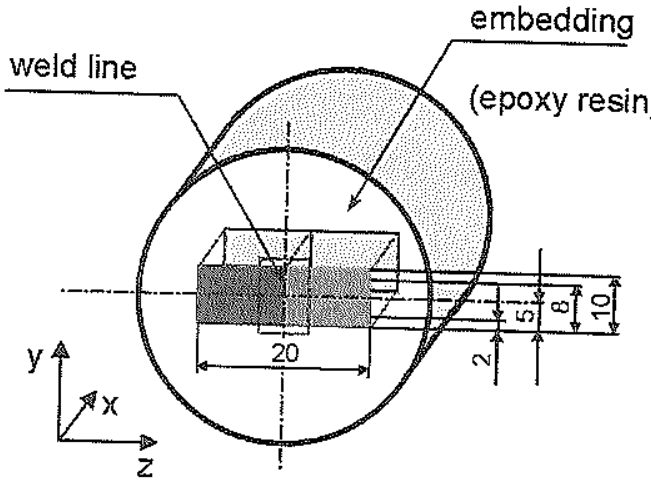

FIGURE 1. (a) Schematic representation of a doubly injection-molded sample showing front weld line and (b) the measuring lines (at 2, 5, and $8 \mathrm{~mm}$ from the sample edge) parallel to the injection direction and across the weld line. (Color version is available on WileylnterScience)
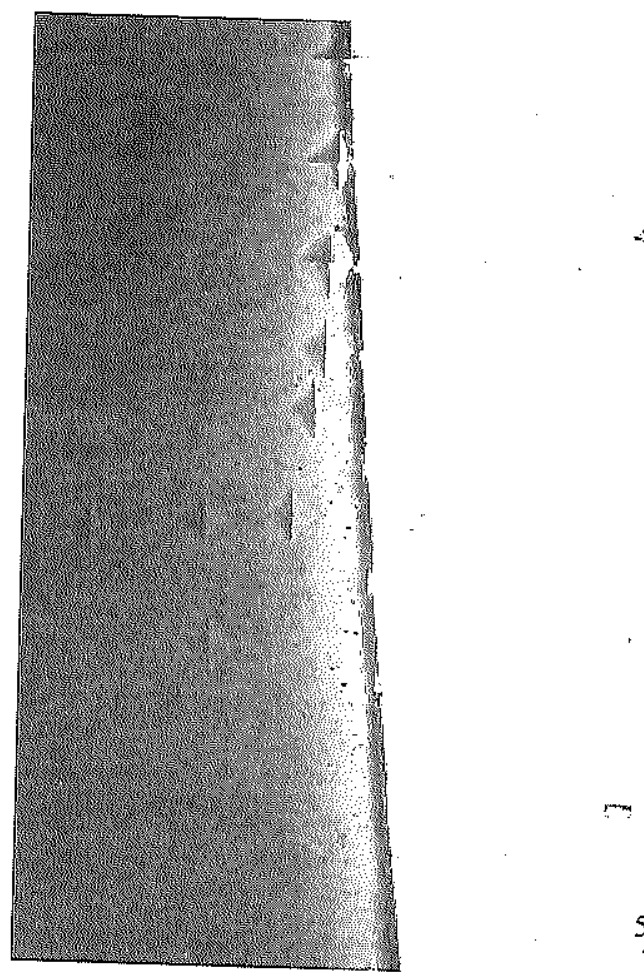

FIGURE 2. Optical micrograph of indentations at the surface of an injection molded PC sample near the weld line area (left-hand side with pigment). 


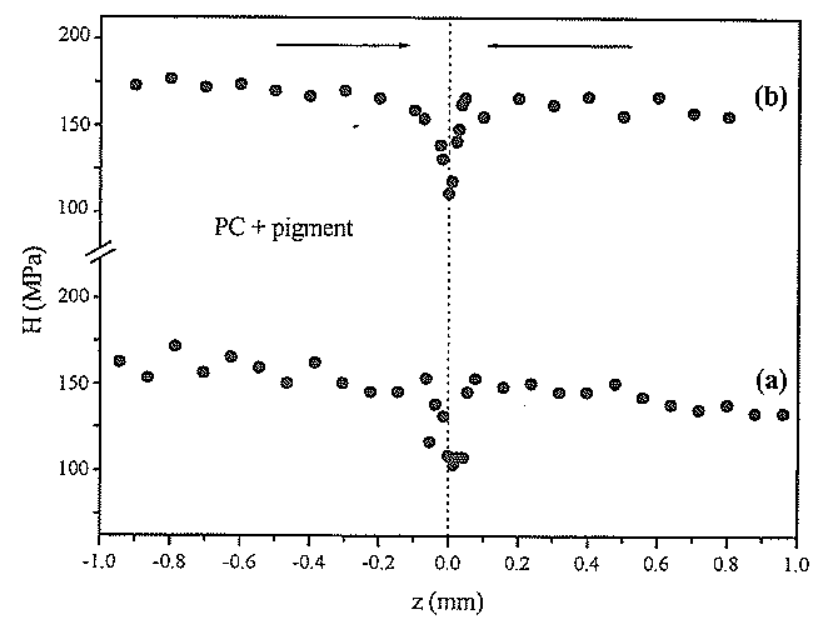

FIGURE 3. Microhardness, $H$, measured at the surface of the molding along the injection direction, $z$, for $P C$ with melt temperature of $270^{\circ} \mathrm{C}$. Arrows denote the direction of the two opposing fronts: measurements are performed along the injection direction (Fig. 1) at a distance from the sample edge as follows: (a) $-2 \mathrm{~mm}$ and (b) $-5 \mathrm{~mm}$. The left part of the sample contains a pigment. The right one does not contain the pigment.

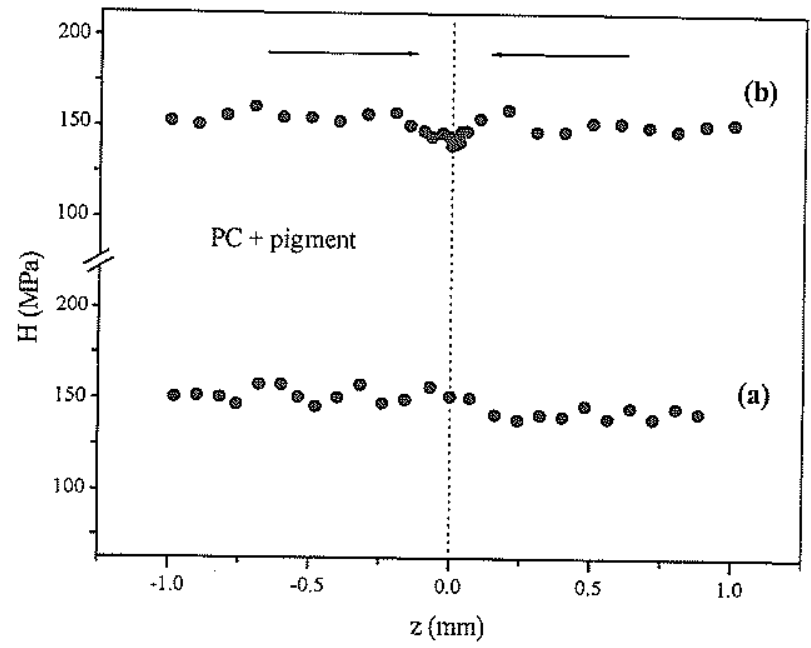

FIGURE 4. Microhardness, $H$, measured at the surface of the molding along the injection direction, $z$, for $P C$ with melt temperature of $300^{\circ} \mathrm{C}$. Arrows denote the direction of the two opposing fronts: measurements are performed. along the injection direction (Fig. 1) at a distance from the sample edge as follows: (a) $-2 \mathrm{~mm}$ and (b) $-5 \mathrm{~mm}$. The left part of the sample contains the pigment. 


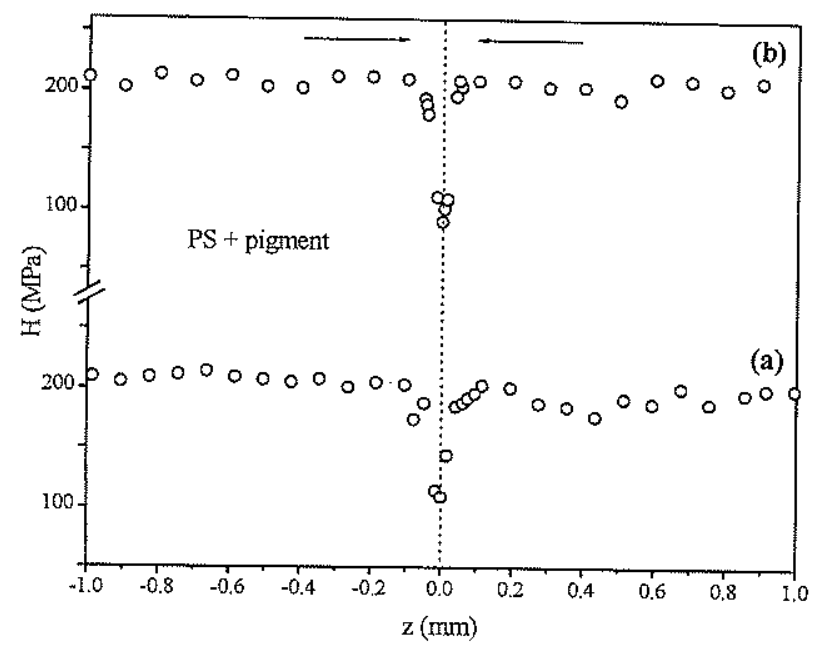

FIGURE 5. Microhardness, $H$, measured at the surface of the molding along the injection direction, $z$, for PS with a melt temperature of $230^{\circ} \mathrm{C}$. Arrows denote the direction of the two opposing fronts: measurements are performed along the injection direction (Fig. 1) at distance from the sample edge: (a) $-2 \mathrm{~mm}$ and (b) $-5 \mathrm{~mm}$. Left part of the sample contains the pigment.

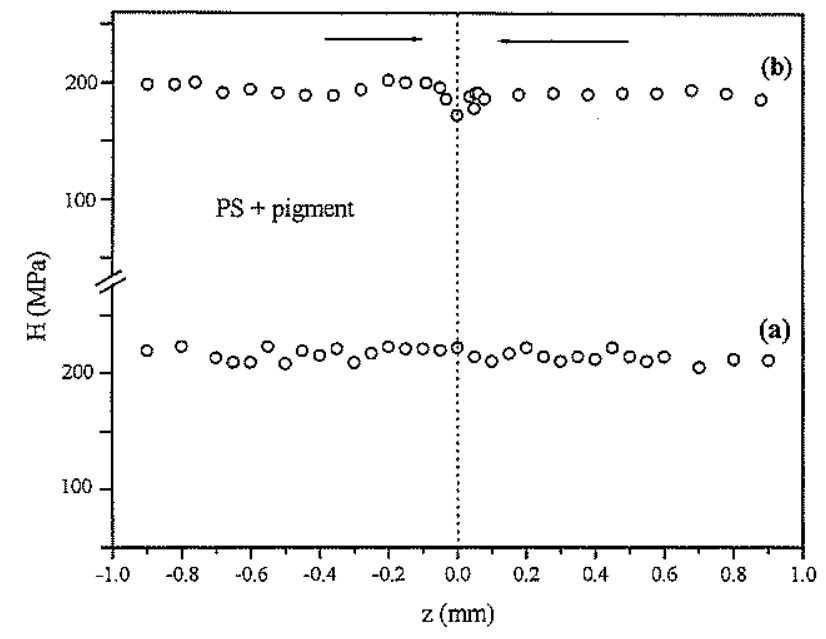

FIGURE 6. Microhardness, $H$, measured at the surface of the molding along the injection direction, $z$, for PS with a melt temperature of $270^{\circ} \mathrm{C}$. Arrows denote the direction of the two opposing fronts: measurements are performed along the injection direction (Fig. 1) at distance from the sample edge: (a) $-2 \mathrm{~mm}$ and (b) $-5 \mathrm{~mm}$. Left part of the sample contains the pigment. 